\title{
A Rare Cause for Acute Abdomen: Gastric Volvulus- Case Report
}

\author{
Murat Kendirci $^{1 *}$ and Nurdan Fidan ${ }^{2}$ \\ ${ }^{1}$ Department of General Surgery, Hitit University Research and Education Hospital, Turkey \\ ${ }^{2}$ Department of Radiology, Hitit University Research and Education Hospital, Turkey \\ Submission: September 04, 2016; Published: September 27, 2016
}

*Corresponding author: Murat Kendirci, Department of General Surgery, Hitit University Corum Education and Research Hospital, Corum, Turkey, Tel: +905052590283; Email: drkendirci@yahoo.co.uk

\begin{abstract}
Summary: Gastric volvulus, which is a rare cause of abdominal pain and acute abdomen, is a pathology that can be mortal via leading to organ necrosis and perforation. Radiological images can be diagnostic in gastric volvulus diagnosis which may get in mind by the presence of Borchardt triad.

Case: Here we present an elderly patient presenting with Borchardt triad. To make a differential diagnosis among the causes of severe abdominal pain and tenderness, computerized tomographic screening revealed torsion at the gastric level with diaphragmatic herniation. Patient was underwent laparotomy and an accompanying thoracal herniation was seen. After the detorsionation of the stomach, accompanying diaphragmatic herniation repair was followed by gastropectia. After a five days follow up, patient was discharged with a good clinical course.

Discussion: Gastric volvulus is a rare condition causing abdominal severe pain and sometimes acute abdomen with consequent complications. Borchardt triad should be kept in mind to alert the physician regarding the possible gastric volvulus. In the absence of consequent complications, gastric volvulus can be cured by operative detorsiasyon and gastropectia. Concomitant pathologies like adhesion or herniation should be repaired at the same operations.
\end{abstract}

Keywords: Gastric volvulus; Borchardt; Whirl Sign

\section{Introduction}

Numerous patients use to refer to emergency rooms everyday due to abdominal pain all over the world. One of the rare conditions, among the several etiologies in these patients, is gastric volvulus. This pathology, which occurs via rotation of the stomach around its own axis more than 1800, may cause acute abdomen as well as may be asympthomatic [1]. Diaphragmatic hernia, which is suggested as antecedent of volvulus, usually accompanies, however, occurrence among patients with unusually mobile stomach has been reported in the literature [2]. It is difficult to diagnose gastric volvulus because there are no specific clinical and laboratory findings. Advanced experience is required to identify the torsion and atypical replacement of stomach which is radiologically diagnostic [3]. In our case, we aimed to present a patient who developed acute abdomen due to gastric volvulus and discuss the treatment options in the literature.

\section{Case Report}

A68years old man was referred to our emergency department with severe abdominal pain. The detailed health history of the patient revealed that he had frequent epigastric pain during last one year and proton pump inhibitor drugs were prescribed in outpatient visits, however, he had irregular drug usage. He did not undergo endoscopic or radiological examination. He also complained of feeling bloated and dyspepsia starting approximately 30 minutes after digestion and lasting for about two hours. He had no history of operations or trauma, and any concomitant chronic disease or drug usage.

His abdominal pain which became stronger progressively before his admittance was accompanied with difficulty in breathing and chest pain during inspiration, loss of appetite, palpitation and bad smelling vomiting. In the physical examination, he had generalized abdominal tenderness, defense in epigastric region, decreased bowel sounds and coarsening in respiratory sounds at both lower zones of lungs. Arterial blood pressure was $90 / 60 \mathrm{mmHg}$, and pulse was 90 beats/ minute/rhythmic. In the biochemical and hematological tests; hemoglobin was $13.0 \mathrm{~g} / \mathrm{dL}$, white blood cells were $12.490 / \mathrm{mm} 3$, C-reactive protein was $8,7 \mathrm{mg} / \mathrm{dL}$ and other parameters were normal. In addition to before mentioned, considerable abdominal 
distention was diagnosed in general surgery consultation which held approximately 30 minutes after admittance to emergency room.

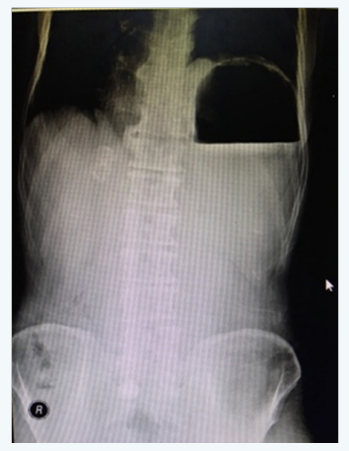

Figure 1: The nomogram for determining the rain.

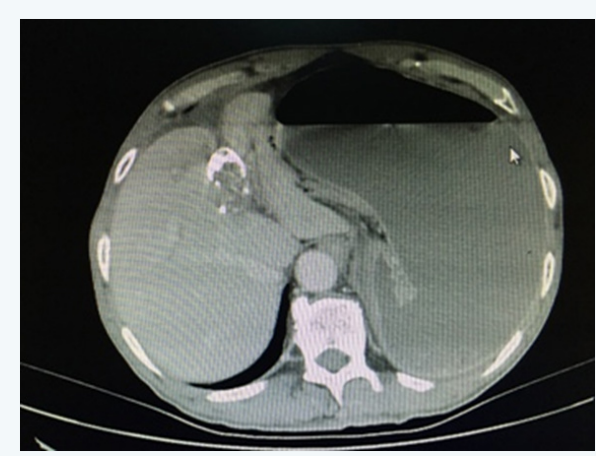

Figure 2: Computerized abdominal tomography screening revealed left thoracic shifting of extremely dilated stomach. Also, atypical replacement of pylorus and fundus was indicating to gastric volvulus.

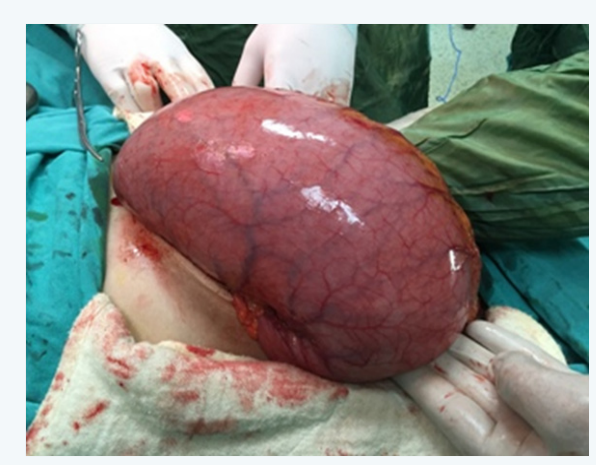

Figure 3: Gastric dilatation and volvulus observed during operation.

Nasogastric tube decompression was planned but not succeeds despite 3 attempts. Posteroanterior chest and direct abdominal X-ray revealed expanded mediastinum, elevated left diaphragm and left sided increased gastric gas (Figure 1). Computerized abdominal tomography screening revealed left thoracic shifting of extremely dilated stomach. Also, atypical replacement of pylorus and fundus was indicating to gastric volvulus (Figure 2). The patient was hospitalized with gastric volvulus diagnosis and preoperative resuscitation with fluid rehydration initiated. At the operation, surgical exploration through median incision revealed that extremely dilated stomach filled the half of abdomen and rotated almost 180 degrees around the small curvature - big curvature axis (mesenteroaxial volvulus) (Figure 3). Also, pylorus and fundus were herniated to left thorax through a $20 \times 10 \mathrm{~cm}$ defect located left lateral side of left diaphragmatic crus as is shown in radiological investigations.

There was approximately $150 \mathrm{cc}$ of reactional fluid in the abdominal cavity. The operative procedure applied was reduction of the herniated stomach from the thoracic cavity back to abdominal cavity with manual detorsion. After detorsion, nasogastric tube was introduced and $2500 \mathrm{cc}$ gastric fluid was drained, and latter let subsequent stomach relaxation and its viability became visually better. In surgical repair, diaphragmatic hernia was closed by primary suturing with separated polypropilen sutures, and gastropexy was performed regarding to proper anatomic position. The patient had nasogastric decompression for two days postoperatively. Oral intake was started on the postoperative day three and standard hospital meal at day four. He did not have any complications and discharged at postoperative day 5 .

\section{Discussion}

Gastrointestinal system volvulus is among the abdominal pathologies at all ages. Gastric volvulus is a very rare condition and occurs as a result of the rotation of stomach around its short or long axis more than 180 degrees, and incidence does not differ according to race or gender. In the literature, most of the patients have concomitant intraabdominal pathologies such as hiatal hernia, pyloric stenosis or intraabdominal adhesions, however, in the absence of concomitant pathology, it is named as idiopathic gastric volvulus [1]. Underlying pathology is suggested to impair the gastrointestinal system physiology and lead to volvulus. Gastric volvulus can be classified in four subgroups according to the formation mechanisms;

a. Type 1: is the rotation of stomach around pylorus cardia axis (organoaxial form). It is the most common type (59\%) and seen mostly in elderly ages and concomitant diaphragmatic defects are more common.

b. Type 2: is the rotation of stomach around small - big curvature axis (mesenteroaxial form). It is less common (29\%) and mostly seen in childhood.

c. Type 3: is the mixture of the Type 1 and Type 2 in the same patient (combined form) and is the rarest form (2\%).

d. Type 4: there is no anatomical points clarified in the operation as torsion axis (unclassified form) and is $10 \%$ of the cases [4].

Clinical presentation with epigastric pain, vomiting and difficulty in nasogastric tube replacement is the Borchardt 
triad and helps the diagnosis [5]. Three quarters of the patients have this triad and no specific symptom has been reported to support the diagnosis. Our patient had Borchardt triad however this rare entity was not recognized at that moment. As our patient did not have any specific laboratory results, advanced diagnostic tools were considered. In gastric volvulus cases esophagus-stomach-duodenum roentgenogram with Barium and contrast thoracoabdominal computerized tomography are recommended however our patient had Borchardt triad and failure in nasogastric tube replacement and co-existing vomiting complicated the Barium swallowed procedure.

Computerized thorcoabdominal tomography screening revealed dilated stomach with pylorus and fundus being in left thorax which are pathognomonic for volvulus. In the literature, radiologic whirl sign is suggested diagnostic for volvulus however is present in intestinal and colonic Volvulus [6]. Shifting of pylorus to left thorax and failure in nasogastric tube replacement supported the diagnosis of gastric volvulus in our case. In review of the literature, chronic gastric volvulus cases may present with a wide symptom spectrum including being asymptomatic to nonspecific symptoms like epigastric pain, dyspepsia or bloating, and may cause serious complaints such as dyspnea due to pressure on lungs, palpitation due to pressure on pericardium and dysphagia due to pressure on esophagus [2].

Patients may present with more specific symptoms such as vomiting soon after eating. Symptoms usually subside after vomiting and nasogastric tube replacement. However, progression to serious urgent conditions such as strangulation, incarceration, necrosis, and perforation may quickly occur [1]. Our patient indicated vomiting, palpitation, difficulty in respiration and chest pain in inspiration. At the physical examination abdominal distention, epigastric tenderness and decrease in bowel sounds were found. Clinical findings were indicating an obstructed gastrointestinal system. The latter was the reason for the emergency medicine doctors to consider situation as acute abdomen requiring laparotomy and consult general surgery without any further diagnostic examination. While medical history, physical examination, laboratory test and roentgenograms were not enough for differential diagnosis tomographic evaluation diagnosed the gastric volvulus.

The treatment of gastric volvulus is surgical [7]. It can be treated successfully by laparotomy or laparoscopic approaches
[4]. Traditional treatment approach includes three steps in uncomplicated patients: detorsion of stomach, repair of concomitant and/or initiator condition like diaphragmatic hernia and gastropexy [8]. In chronic cases treatment of coexisting intraabdominal pathologies may be treated. In case of progression to gastric necrosis or perforation immediate surgical operation is necessary and perforation repair must be added [3]. Our patient underwent laparotomy as the choice of the author. After pulling uncomplicated torsioned stomach into abdominal cavity from thoracic defect and repositioning, accompanying diaphragmatic hernia was repaired. In order to avoid recurrence, gastropexy by fixing big curvature was performed.

\section{Conclusion}

In the patient we presented, Type 2- mesenteroaxial gastric volvulus with accompanying diaphragmatic hernia was treated surgically before it complicated. Borchardt triad should be kept in mind in patients presenting with abdominal pain and/or acute abdomen at emergency departments and "volvulus" should be considered in differential diagnosis. Difficulty or failure in nasogastric tube insertion should remind gastric volvulus. Accompanying / initiating pathologies must be searched and concurrently repaired in operation for gastric volvulus.

\section{References}

1. Chau B, Dufel S (2007) Gastric volvulus. Emerg Med J 24(6): 446-447.

2. Kitagawa Y, Dempsey DT (2016) (çev:Bostancı EB, Çolakoğlu MK): Mide volvulusu. In: Schwartz Onuncu baskı, Brunicardi FC (Eds.), (çev. editörü: Özmen M), Güneș Tıp Kitapevleri 1090.

3. Enis Dikicier, Fatih Altıntoprak, Gökhan Akbulut (2012) Ender görülen bir akut karın sendromu etyolojisi: idiopatik mide volvulusu- bir olgu sunumu. Ulusal Cerrahi Dergisi 28(2): 106-108.

4. Lee TC, Liu KL, Lin MT, Wang HP (2006) Unusual cause of emesis in an octogenerian: organoaxial gatric volvulus associated with paraesophageal diaphragmatic hernia. J Am Geriatr Soc 54(3): 555557.

5. Germanos S, Gourgiotis S, Saedon M (2010) Severe abdominal pain as a result of acute gastric volvulus. Int J Emerg Med 3: 61-62.

6. Hirao K, Kikawada M, Hanyu H, Iwamoto T (2006) Sigmoid volvulus showing 'a whirl sign' on CT. Intern Med 45(5): 331-332.

7. Bawahab M, Mitchell P, Church N, Debru E (2009) Management of acute paraesophageal hernia. Surg Endosc 23(2): 255-259.

8. Chiu CC, Wang W, Wei PL, Lee WJ (2006) Giant diaphragmatic hernia intrathoracic gastric volvulus. Endoscopy 38: 52-53. 
Your next submission with JuniperPublishers will reach you the below assets

- Quality Editorial service

- Swift Peer Review

- Reprints availability

- E-prints Service

- Manuscript Podcast for convenient understanding

- Global attainment for your research

- Manuscript accessibility in different formats ( Pdf, E-pub, Full Text, audio)

- Unceasing customer service

- Track the below URL for one-step submission

http://juniperpublishers.com/online-submission.php 